\title{
The hazards of smoking in women: results from the Million Women Study
}

Smoking is associated with many diseases and remains a major cause of mortality. The Million Women Study is a large UK prospective cohort study of women born in the second quarter of the 20th century, collecting data for a broad range of health issues. Women were recruited and sent questionnaires that included lifestyle factors such as smoking at baseline, 3 years and 8 years. After excluding women with previous smoking-associated diseases, 1.2 million invited participants were followed up for mortality for a mean of 12 years via national mortality records.

Current smokers had a threefold increase in mortality compared with never-smokers, with adjusted mortality rate ratio increasing almost linearly with the number of cigarettes smoked at baseline. Relative risks were highest for deaths due to chronic lung disease and lung cancer. Ex-smokers had lower but still raised relative risks. Applying their results to a hypothetical population, the authors calculated that smokers lose 11 years of life span.

The large sample size would minimise any selection bias of the Million Women Study, which recruited volunteers within the UK breast screening programme. With an average starting age of 19 years, this cohort is felt to represent the first generation of women in the UK where the long-term effects of smoking throughout adult life can be observed. The authors provided figures on the proportional reduction in mortality by stopping smoking before certain ages; used in the appropriate context, these data may be a useful tool for smoking cessation advice.

- Pirie K, Peto R, Reeves GK, et al. The 21st century hazards of smoking and benefits of stopping: a prospective study of one million women in the UK. Lancet 2013;381:133-141.

\section{Laurence Si Chong Lok}

Correspondence to Dr Laurence Si Chong Lok, ST4, Lister Hospital, East and North Hertfordshire NHS Trust, Coreys Mill Lane, Stevenage, Hertfordshire SG1 4AB, UK; Isclok@cantab.net

To cite Lok LSC. Thorax 2014;69:4.

Published Online First 8 March 2013

Thorax 2014;69:4. doi:10.1136/thoraxjnl-2013-203451 